OPEN ACCESS

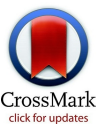

${ }^{1}$ Department of Health Care

Policy, Harvard Medical School,

180 Longwood Avenue, Boston,

MA 02115, USA

2Department of Emergency

Medicine and Leonard D.

Schaeffer Center for Health

Policy and Economics,

University of Southern

California, 635 Downey Way,

VPD Suite 210, Los Angeles, CA

90089-3333, USA

3Department of Medicine,

Massachusetts General

Hospital, Boston, MA, USA

${ }^{4}$ National Bureau of Economic

Research, Cambridge, MA, USA

Correspondence to: A B Jena

jena@hcp.med.harvard.edu

Additional material is published online only. To view please visit

the journal online.

Cite this as: $B M / 2016 ; 353: \mathrm{i} 2923$

http://dx.doi.org/10.1136/bmj.i2923

\section{Differences in incomes of physicians in the United States by race and sex: observational study}

\author{
Dan P Ly, ${ }^{1}$ Seth A Seabury, ${ }^{2}$ Anupam B Jena ${ }^{1,3,4}$
}

\section{ABSTRACT}

OBJECTIVES

To estimate differences in annual income of physicians in the United States by race and sex adjusted for characteristics of physicians and practices.

DESIGN

Cross sectional survey study.

SETTING

Nationally representative samples of US physicians.

\section{PARTICIPANTS}

The 2000-13 American Community Survey (ACS)

included 43213 white male, 1698 black male, 15164 white female, and 1252 black female physicians. The 2000-08 Center for Studying Health System Change (HSC) physician surveys included 12843 white male, 518 black male, 3880 white female, and 342 black female physicians.

\section{MAIN OUTCOME MEASURES}

Annual income adjusted for age, hours worked, time period, and state of residence (from ACS data). Income was adjusted for age, specialty, hours worked, time period, years in practice, practice type, and percentage of revenue from Medicare/Medicaid (from HSC physician surveys).

\section{RESULTS}

White male physicians had a higher median annual income than black male physicians, whereas race was not consistently associated with median income among female physicians. For example, in 2010-13 in the ACS, white male physicians had an adjusted median annual income of $\$ 253042$ (95\% confidence interval \$248670 to \$257 413) compared with \$188230 (\$170 844 to $\$ 205616$ ) for black male physicians (difference $\$ 64812 ; \mathrm{P}<0.001$ ). White female physicians had an adjusted median annual income of \$163234 (\$159912 to 166557) compared with \$152784 (\$137927 to $\$ 167641$ ) for black female physicians (difference $\$ 10450 ; \mathrm{P}=0.17) . \$ 100000$ is currently equivalent to about $£ 69000$ ( $€ 89000$ ). Patterns were unaffected by adjustment for specialty and characteristics of practice in the HSC physician surveys.

\section{WHAT IS ALREADY KNOWN ON THIS TOPIC}

National estimates of differences in annual income between black and white physicians in the US are limited, despite overwhelming evidence that black people earn less than white people in the overall US economy

\section{WHAT THIS STUDY ADDS}

White male physicians earn substantially more than the black male physicians, even after adjustment for characteristics of physicians and practices

Incomes of black and white female physicians are similar, but significantly lower than the incomes of male physicians

\section{CONCLUSIONS}

White male physicians earn substantially more than black male physicians, after adjustment for characteristics of physicians and practices, while white and black female physicians earn similar incomes to each other, but significantly less than their male counterparts. Whether these differences reflect disparities in job opportunities is important to determine.

\section{Introduction}

National estimates of differences in annual income between black and white physicians in the United States are limited, despite evidence from outside healthcare that black workers continue to earn less than white workers over five decades since the Civil Rights Act of 1964. ${ }^{12}$ For example, in 1967 the mean household income for non-Hispanic white people was $\$ 57$ 026, while for black people it was $\$ 30598$. In 2011, incomes were $\$ 76063$ and $\$ 47255$, respectively ${ }^{3}$ (currently equivalent to about $€ 52000$ (€68000) and $€ 32000$ (€42000)).

Physicians reflect a more homogenous group than the overall working population, and focus on this group accounts for some of the factors mediating race differences in income in the overall population, such as education. Physicians' incomes, which are on average much higher, are affected by such factors as choice of specialty, hours worked, and percentage of revenue by insurance type. ${ }^{45}$ Within healthcare, previous studies have suggested that white and black male physicians earn similar annual incomes, even after adjustment for work effort and for characteristics of physicians and practices, but that black female physicians earn less than white female physicians. ${ }^{6-9}$ These studies, however, have relied on small samples of black physicians and contain surveyed income data from nearly two decades before.

In contrast with the limited evidence on race differences in physicians' income, research on sex differences is more robust. Several large studies have shown that female physicians earn less than male physicians, ${ }^{1011}$ even after adjustment for specialty, practice type, and hours worked. ${ }^{12}$ One study estimated that the earnings gap was about $\$ 34000$ in 1987-90 and about $\$ 56000$ in 2006-10. ${ }^{11}$ Moreover, similar sex differences exist among physician researchers and among nurses. ${ }^{1314}$ These sex differences in income also occur internationally; male physicians in the United Kingdom make about 10\% more than their female counterparts. ${ }^{15} 16$

Given persistent differences by race in annual income in the overall US economy, there are reasons to be concerned that these differences persist for physicians as well. It is important to identify race and sex differences 
in the earnings of physicians to highlight the magnitude of the problem. Further, it is important to distinguish whether these differences are driven primarily by factors such as access to higher paying specialties to help guide policy efforts to reduce disparities. We combined data from two recent nationally representative surveys to evaluate differences in income by race and sex among US physicians.

\section{Methods}

Data sources

We used data from two national surveys, each with its own strengths and limitations, to estimate differences in income in black and white physicians.

\section{US Census American Community Survey}

The American Community Survey (ACS) is a nationally representative, cross sectional survey of about three million households annually, administered by the US Census Bureau. The survey is mandatory and is collected by mail, telephone, and personal visits. The survey, which includes civilian and military households, collects information on respondent demographics (age, sex, race), occupation, annual personal earned income, and hours worked. Response rates vary from year to year but range between $93 \%$ and $98 \%$ each year. ${ }^{11}$ We analyzed surveys from 2000 to 2013, the most recent year of the survey.

Each survey respondent self reported information on age, sex, race, occupation, annual earned income, and weekly hours usually worked (based on hours worked at all jobs). We specifically focused on a given physician's personal income earned from labor employment and business income, as opposed to spousal income or income arising from investments. About $13 \%$ of income values for physicians were missing and imputed by the Census Bureau in the ACS. Furthermore, income was censored above an upper bound (that is, topcoded), and values above this topcode, which varied by state and year, were replaced with the median value of income above that topcode in that state and year. For example, in 2005, any income value above a state's topcode was replaced with the median value of income above the topcode within that state in $2005 .{ }^{17}$ About $40 \%$ of physician observations in the ACS had topcoded earnings (about $41 \%$ for white physicians and $47 \%$ for white male physicians).

Physician specialty was unavailable in the ACS, as were characteristics of practices. Based on previous work, we limited analyses to individuals aged $\geq 35$ who were employed in the previous year to focus on those who had completed training. ${ }^{11819}$ Sampling weights were provided by the survey and reflected the survey sampling procedures used to weight all estimates to bring the characteristics of the sample more in agreement with those of the full US population.

The primary strength of the survey compared with previous surveys used to estimate differences in physicians' income by race is its size and national representativeness. For example, across all years the survey included 43213 white male physicians, 1698 black male physicians, 15164 white female physicians, and 1252 black female physicians. In contrast, previous surveys often included fewer than 100 black physicians. ${ }^{68}$ In addition, the survey has been conducted annually since 2000, allowing analyses of trends in the income gap. The primary limitation of the survey is its lack of information on physician specialty and practice characteristics (for example, solo versus group practice, insurance mix, etc), both of which probably influence income. Although previous analyses of differences in income by sex have found that differences persist after adjustment for hours worked, physician specialty, and practice characteristics, ${ }^{12}$ the same might not be true for race differences. We therefore used a second source of data, which included information on physician specialty, hours worked, and practice characteristics, to supplement our analyses.

\section{Center for Studying Health System Change physician surveys}

We analyzed restricted use files of the Community Tracking Study (CTS) physician surveys (2000-01 and 2004-05) and the 2008 Health Tracking physician survey, all of which were conducted by the Center for Studying Health System Change (hereafter referred to as HSC physician surveys). ${ }^{20}$ The CTS surveys in 2000-01 and 2004-05 provide representative samples of physicians across 60 sites in the US (51 metropolitan areas and nine non-metropolitan areas) and are supplemented by a national sample. These surveys were renamed the HSC Health Tracking physician survey in 2008 to reflect the substitution of the clustered 60 site sample design with a national sample. All surveys were administered to physicians and asked questions about practice arrangements, insurance mix, and allocation of time.

The CTS physician survey was conducted by telephone, while the HSC Health Tracking physician survey used a mailed survey. The sample of physicians was randomly drawn from the masterfiles of the American Medical Association (AMA) and the American Osteopathic Association, and primary care physicians were oversampled in the 2000-01 and 2004-05 waves. The response rates for the physician surveys in chronological order were $58.6 \%, 52.4 \%$, and $61.9 \%$. As above, we limited analyses to individuals aged $\geq 35$.

The primary strength of the HSC physician surveys was the inclusion of a comprehensive set of characteristics of physicians and practices that probably influence income. Each respondent self reported information on age, sex, race, net income from the practice of medicine (after expenses but before taxes), number of hours spent in all medically related activities in the last week, years in practice, practice type (solo/two physicians, group practice (three or more physicians), HMO (health maintenance organization, a medical insurance group that provides health services for a fixed annual fee) based, medical school associated, hospital based, and other), percentage revenue from Medicare, percentage revenue from Medicaid, and specialty type (internal medicine, family/general practice, pediatrics, medical 
specialties, surgical specialties, psychiatry, and obstetrics/gynecology). Income was imputed for $4 \%$ of physicians in 2008 and for 18\% in 2004-05 and in 2000-01 with sequential hot deck imputation. ${ }^{21}$ The primary limitations of the HSC surveys were that the number of black physicians was considerably lower than in the ACS (518 black male and 342 black female physicians overall) and that the most recent survey was completed in 2008. Nonetheless, analysis of the HSC physician surveys is important to assess whether differences income by race observed in the ACS are likely to be robust to adjustment for detailed physician and practice characteristics.

\section{Analyses}

American Community Survey (ACS)

We estimated a multivariable median (also known as quantile) regression of annual income as a function of age (35-39, 40-49, 50-59, and $\geq 60$ ), sex, race (non-Hispanic white and non-Hispanic black), hours worked ( $\leq 39,40-49,50-59$, and $\geq 60$ hours), state of residence (to account for the possibility that black physicians could practice in states with lower mean physician income), time period (2000-04, 2005-09, 2010-13), and full interactions between sex, race, and time period. Our analyses used median regression because of topcoding of income and right sided skewness of the income distribution. ${ }^{18}$ Median regressions are unaffected by topcoding and right sided skewness because fewer than half of physicians had topcoded earnings. ${ }^{18}$ We computed adjusted median income according to race, sex, and time period, holding other covariates at their mean values. For categorical variables such as state, we computed adjusted values at the means of the individual indicator variables (that is, reflecting the mean proportion of the sample in each category-for example, the proportion of the sample in a given state). In each time period, we first compared adjusted median income between male and female physicians and between white and black physicians. We then compared adjusted median incomes across race-sex subgroups (that is, white males, black males, white females, black females). Values were normalized to 2013 \$ with the consumer price index. We used robust standard errors to adjust for heteroskedasticity.

\section{Health System Change (HSC) physician surveys}

Physician data were analyzed with the complex survey modules in Stata version 13.1 to account for the sampling structure of the survey. Given income was reported as a continuous measure in the 2000-01 and 2004-05 surveys but as categorical variable in 2008, in our baseline analysis we recoded income into the following categories: <\$100 000; \$100 001-150 000; \$150 001-200 000; $\$ 200001-250000$; and $>\$ 250000$. Values were normalized to 2008 \$ by using the consumer price index; we normalized values from the 2000-01 and 2004-05 survey waves to 2008 \$ to preserve the income categories used in the 2008 HSC survey.

Because income was categorized, we estimated a multivariable ordered logit regression of categorical income as a function of age (same categories as above), sex, race (categorized as non-Hispanic white and non-Hispanic black), and hours worked (same categories as above), thereby excluding any variables that could not be adjusted for in the analysis using the ACS. The purpose of this analysis was to assess whether a similar pattern of differences in income by race was observed in both the HSC physician surveys and ACS when we adjusted for a similar set of variables. To then assess whether differences in income by race were affected by adjustment for additional physician and practice characteristics, we re-estimated the model by also including years in practice, practice type, percentage revenue from Medicare, percentage revenue from Medicaid, and specialty type. We included survey wave indicators to account for the three cross sections of the HSC physician surveys. We computed the adjusted distribution across income categories by race-sex subgroup, holding other covariates at their mean values. We again used robust standard errors to adjust for heteroskedasticity.

\section{Sensitivity analyses}

We conducted several sensitivity analyses. We repeated our ACS analyses using log of median annual income instead of median annual income as the dependent variable (table A in appendix), using continuous age and hours worked rather than categorical age and hours worked (table B in appendix), including metropolitan status (table $C$ in appendix; this variable existed in the ACS starting in 2005), limiting the sample to the years 2000-08 (table D in appendix), using hourly wage instead of annual median income as the dependent variable (table E in appendix), and not using survey weights (table $\mathrm{F}$ in appendix).

For the HSC analyses, although our baseline analysis used categorical income as the primary dependent variable, in sensitivity analyses we estimated a multivariable linear regression using the continuous income values listed in the 2000-01 and 2004-05 survey waves but replacing the income categories in 2008 with what the median value of that category would be in 2004-05 (table $\mathrm{H}$ in appendix). We also repeated our baseline analysis with additional adjustment for weeks worked (table I in appendix).

\section{Patient involvement}

No patients were involved in setting the research question or the outcome measures, nor were they involved in developing plans for design or implementation of the study. No patients were asked to advise on interpretation or writing up of results. There are no plans to disseminate the results of the research to study participants or the relevant patient community

\section{Results}

Findings from American Community Survey (ACS)

Table 1 reports characteristics of physicians in the ACS, which included 43213 white men, 1698 black men, 15164 white women, and 1252 black women. Mean annual income was highest among white male 


\begin{tabular}{|c|c|c|c|c|}
\hline & $\begin{array}{l}\text { White men } \\
(n=43213)\end{array}$ & $\begin{array}{l}\text { Black men } \\
(n=1698)\end{array}$ & $\begin{array}{l}\text { White women } \\
(n=15164)\end{array}$ & $\begin{array}{l}\text { Black women } \\
(n=1252)\end{array}$ \\
\hline \multicolumn{5}{|l|}{ Age (years): } \\
\hline Mean (SD) & $53.2(10.9)$ & $51.1(10.8)$ & $47.8(8.9)$ & $46.0(8.5)$ \\
\hline $35-39$ & 11.4 & 15.8 & 20.8 & 26.4 \\
\hline $40-49$ & 28.1 & 33.1 & 39.1 & 41.5 \\
\hline $50-59$ & 32.6 & 29.9 & 29.7 & 24.2 \\
\hline$\geq 60$ & 28 & 21.2 & 10.4 & 7.8 \\
\hline \multicolumn{5}{|l|}{ Annual income (\$): } \\
\hline Mean (SD) & $255383(154508)$ & $210544(143857)$ & 174106 (128499) & $166833(120811)$ \\
\hline Median & 230050 & 174238 & 140160 & 141825 \\
\hline$\leq 100000$ & 17.7 & 26.9 & 33.7 & 33.5 \\
\hline $100001-150000$ & 11.8 & 15.3 & 19.5 & 20.7 \\
\hline $150001-200000$ & 13.4 & 15.5 & 16.4 & 19.5 \\
\hline $200001-250000$ & 10.2 & 8.4 & 7.9 & 8.1 \\
\hline$>250000$ & 46.9 & 33.9 & 22.4 & 18.3 \\
\hline \multicolumn{5}{|l|}{ Hours worked/week: } \\
\hline Mean (SD) & $51.2(16.0)$ & $51.9(17.4)$ & $45.2(16.3)$ & $48.0(14.9)$ \\
\hline$\leq 39$ & 13.6 & 12.1 & 26.7 & 14.9 \\
\hline $40-49$ & 24.3 & 30.5 & 29.5 & 39.1 \\
\hline $50-59$ & 24.5 & 18 & 20.1 & 19.7 \\
\hline$\geq 60$ & 37.6 & 39.3 & 23.7 & 26.4 \\
\hline
\end{tabular}

physicians ( $\$ 255383$ ), followed by black male physicians ( $\$ 210544 ; \mathrm{P}<0.001$ compared with white males), white female physicians ( $\$ 174106 ; \mathrm{P}<0.001$ compared with white males), and black female physicians ( \$166 833; $\mathrm{P}<0.001$ compared with white males). Median annual incomes by race and sex were lower than mean annual incomes ( $\$ 230050$ for white male physicians, \$174238 for black male physicians, $\$ 140160$ for white female physicians, and $\$ 141825$ for black female physicians). Mean age was highest among white men at 53.2, which was about 7 years older than the lowest mean age of 46 among black women. The average number of hours worked per week was similar between white and black male physicians (51.2 and 51.9 hours, respectively; $\mathrm{P}=0.08$ ), both of which were greater than for white and black female physicians ( 45.2 and 48.0 hours, respectively).

Differences in median income by race persisted after multivariable adjustment and did not significantly vary

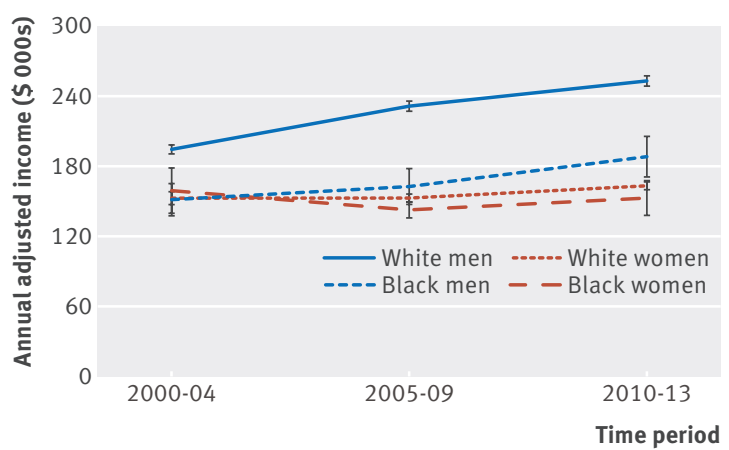

Fig 1 | Trends in adjusted annual median income of US physicians in American Community Survey, by race-sex subgroup, 2000-13. Adjusted earned incomes are predicted values from multivariable median regression of annual employment income as function of age (35-39, $40-49,50-59$, and $\geq 60$ ), sex, race, hours worked ( $\leq 39$, $40-49,50-59$, and $\geq 60$ hours), time period, state fixed effects, and full interactions between race, sex, and time period. All \$ values normalized to 2013 \$ according to consumer price index

over the study period (table 2). For example, during 2000-04, the adjusted difference in median income was \$27108 (\$183258v \$156150; 95\% confidence interval for difference $\$ 18118$ to $\$ 36097$ ), compared with $\$ 37841$ in 2005-09 ( $\$ 209803 v$ \$171962; $\$ 31068$ to $\$ 44613 ; \mathrm{P}=0.06$ for difference compared with difference in 2000-04), and \$34 141 in 2010-2013 (\$228585v \$194444; \$21746 to $\$ 46535 ; \mathrm{P}=0.37$ for difference compared with difference in 2000-04). Differences in median income by sex were also present throughout the study period and were larger in magnitude than differences by race. For example, during 2010-13, the adjusted median annual income among male physicians was $\$ 85921$ higher than among female physicians (\$249164 v \$163244; \$80 449 to \$91393).

Race-sex subgroup analysis showed that income differences by race were predominantly driven by differences within men. In all periods, white men earned more than black men, whereas among women, income was inconsistently associated with race (fig 1). For example, in 2010-13, white male physicians had

Table 2 | Trends in adjusted median annual income (\$) of US physicians in American Community Survey, according to race and sex, 2000-13*

\begin{tabular}{|c|c|c|c|}
\hline & \multicolumn{3}{|c|}{ Adjusted median earned income $(95 \% \mathrm{Cl})$} \\
\hline & $2000-04$ & 2005-09 & 2010-13 \\
\hline \multicolumn{4}{|l|}{ Race: } \\
\hline White $(n=58377)$ & 183258 (179919 to 186597$)$ & 209803 (206611 to 212995) & 228585 (225184 to 231986$)$ \\
\hline Black $(n=2950)$ & 156150 (147382 to 164919$)$ & $171962(165180$ to 178744$)$ & 194444 (182058 to 206830) \\
\hline Differencet & 27108 (18118 to 36097$)$ & 37841 (31 068 to 44613 ) & 34141 (21746 to 46535$)$ \\
\hline \multicolumn{4}{|l|}{ Sex: } \\
\hline Men $(n=44911)$ & 191633 (187819 to 195446$)$ & 226810 (222814 to 230806 ) & 249164 (244785 to 253543$)$ \\
\hline Women $(n=16416)$ & 153675 (149089 to 158261$)$ & 153623 (150167 to 157079$)$ & 163244 (159817 to 166670$)$ \\
\hline Difference $\neq$ & 37958 (32529 to 43386) & 73187 (68 032 to 78342 ) & 85921 (80 449 to 91393) \\
\hline \multicolumn{4}{|c|}{$\begin{array}{l}\text { *Authors' calculation using income data from US Census American Community Survey } 2000-13 \text {. Adjusted earned incomes are predicted values from } \\
\text { multivariable median regression of annual employment income as function of age (categorized as } 35-39,40-49,50-59 \text {, and } \geq 60 \text { ), sex, race, hours worke } \\
\text { (categorized as } \leq 39,40-49,50-59 \text {, and } \geq 60 \text { hours), time period, state fixed effects, and full interactions between race, sex, and time period. All } \$ \text { values } \\
\text { normalized to } 2013 \$ \text { according to consumer price index. } \\
\text { tP value for difference compared with } 2000-04 \text { was } 0.06 \text { for } 2005-09 \text { and } 0.37 \text { for } 2010-13 \text {. } \\
\text { fP value for difference compared with 2000-04 was }<0.001 \text { for } 2005-09 \text { and }<0.001 \text { for 2010-13. }\end{array}$} \\
\hline
\end{tabular}


adjusted median annual income of $\$ 253042$ (95\% confidence interval \$248670 to \$257413) compared with $\$ 188230$ (\$170 844 to $\$ 205616$ ) for black male physicians (difference $\$ 64812 ; \mathrm{P}<0.001$ ), whereas white female physicians had adjusted median annual income of \$163234 (\$159912 to \$166557) compared with \$152784 (\$137927 to \$167641) for black female physicians (difference \$10450; $\mathrm{P}=0.17$ ). Differences in median income by sex were present among both white and black physicians. White men earned more than white women in all periods, whereas black men had similar adjusted median income to black women in 2000-04 but higher income in subsequent periods.

Results were largely unaffected when we used the log of median annual income instead of median annual income as the dependent variable (table A in appendix), used continuous age and hours worked rather than categorical age and hours worked (table B in appendix), included metropolitan status as a control (table $\mathrm{C}$ in appendix), limited the sample to the years 2000-08 (table D in appendix), used hourly wage instead of annual median income as the dependent variable (table $\mathrm{E}$ in appendix), and did not use survey weights (table $\mathrm{F}$ in appendix).

\section{Findings from Health System Change (HSC) physician surveys}

Because differences in physicians' income by race estimated from the ACS did not adjust for race differences in physician specialty or practice characteristics that might confound our estimates, we also analyzed data from the HSC physician surveys. Table 3 lists the characteristics of the study population, which included 12843 white male physicians, 518 black male physicians, 3880 white female physicians, and 342 black female physicians across all years. Within each race-sex subgroup, mean physician age and hours worked were broadly similar to the ACS. White male physicians had the highest average number of years in practice. Black male physicians were more likely to work in solo practice, while white male physicians were more likely to work in group practices. White male physicians had the

\begin{tabular}{|c|c|c|c|c|}
\hline & White men $(n=12843)$ & Black men $(n=518)$ & White women $(n=3880)$ & Black women (342) \\
\hline Mean (SD) & $51.4(10.2)$ & $50.4(9.0)$ & $46.4(7.9)$ & $44.2(7.0)$ \\
\hline $35-39$ & 11.9 & 8.9 & 20.8 & 34.2 \\
\hline $40-49$ & 34.4 & 42.3 & 48.5 & 40.9 \\
\hline$\geq 60$ & 20.2 & 14.7 & 5.7 & 2.6 \\
\hline \multicolumn{5}{|l|}{ Annual income (\$): } \\
\hline$\leq 100000$ & 9.5 & 14.9 & 26.7 & 21.1 \\
\hline $100001-150000$ & 17.8 & 25.9 & 32.7 & 37.7 \\
\hline $150001-200000$ & 25 & 26.3 & 21 & 26.9 \\
\hline \multicolumn{5}{|l|}{ Hours worked/ week: } \\
\hline Mean (SD) & $54.4(15.0)$ & $55.8(17.6)$ & $47.0(16.0)$ & $51.4(15.4)$ \\
\hline$\leq 39$ & 10.8 & 9.3 & 28.5 & 16.1 \\
\hline $40-49$ & 20.9 & 23.4 & 24.9 & 27.5 \\
\hline $50-59$ & 28 & 22.8 & 22.9 & 22.8 \\
\hline$\geq 60$ & 40.3 & 44.6 & 23.7 & 33.6 \\
\hline Mean (SD) years in practice & $21.4(10.7)$ & $18.4(9.6)$ & $15.4(7.9)$ & $13.7(7.5)$ \\
\hline \multicolumn{5}{|l|}{ Practice type: } \\
\hline Solo/2 physicians & 33.9 & 44.4 & 28 & 29 \\
\hline Group practice $\geq 3$ physicians & 35.2 & 20.1 & 28 & 16.7 \\
\hline $\mathrm{HMO}$ & 3.3 & 4.1 & 4.9 & 6.1 \\
\hline Internal medicine & 14.6 & 26.6 & 16.9 & 18.4 \\
\hline Family/general practice & 24.2 & 22.4 & 25.3 & 21.1 \\
\hline Pediatrics & 8.3 & 10.8 & 20.2 & 26.3 \\
\hline Medical specialties & 25.2 & 14.9 & 19.6 & 13.5 \\
\hline Surgical specialties & 18.8 & 11.4 & 4.5 & 4.7 \\
\hline Psychiatry & 4.8 & 6.4 & 7.1 & 5.9 \\
\hline Obstetrics/gynecology & 4.2 & 7.5 & 6.4 & 10.2 \\
\hline
\end{tabular}

$\mathrm{HMO}=$ health maintenance organization. 
highest percentage of revenue from Medicare and lowest percentage of revenue from Medicaid. White male physicians were the most likely to be in medical or surgical specialties, whereas black male physicians were the most likely to be in internal medicine and black women were the most likely to be in pediatrics.

We observed similar income patterns by race compared with the ACS. For example, before multivariable adjustment, $27.3 \%$ of white male physicians made $\$ 150000$ or less compared with $40.8 \%$ of black male physicians (absolute difference 13.5\%, 95\% confidence interval $9.6 \%$ to $17.4 \%$ ); in contrast, $59.4 \%$ of white female physicians made $\$ 150000$ or less compared with $58.8 \%$ of black females physicians (absolute difference $0.6 \%, 4.9 \%$ to $6.0 \%$ ). Conversely, $30.9 \%$ of white male physicians made above $\$ 250000$ compared with $18.3 \%$ of black male physicians (absolute difference $12.5 \%, 8.5 \%$ to $16.6 \%$ ), and $9.6 \%$ of white female physicians made above $\$ 250000$ compared with $7.3 \%$ of black female physicians (absolute difference 2.3\%, $-0.9 \%$ to $5.6 \%$ ).

Estimated differences in income by race were similar irrespective of whether we adjusted for physician age and hours worked alone (similar to our analysis of the ACS) or whether we in addition adjusted for physician specialty and practice characteristics (table $G$ in appendix). For example, when we adjusted only for physician age and hours worked (fig 2), 36.9\% (95\% confidence interval $35.7 \%$ to $38.0 \%$ ) of white male physicians had adjusted annual income over $\$ 250000$ compared with $21.8 \%$ (17.3\% to $26.3 \%$ ) of black male physicians $(\mathrm{P}<0.001$ for difference), and 15.8\% (14.5\% to $17.1 \%$ ) of white female physicians earned more than $\$ 250000$ compared with $13.6 \%$ (10.7\% to $16.5 \%$ ) of black female physicians ( $\mathrm{P}=0.09$ for difference). When we also adjusted for physician specialty and practice characteristics (fig 3), 35.4\% (34.4\% to 36.5\%) of white male physicians had adjusted income over $\$ 250000$

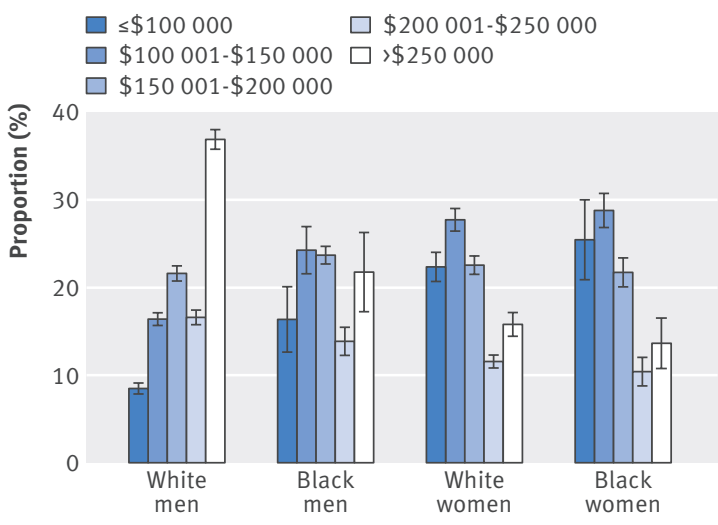

Fig 2 | Income distribution of US physicians in HSC physician surveys $(2000-01,2004-05,2008)$ by race and sex. Adjusted income categories predicted categories from multivariable ordered logit regression of net income from practice of medicine as function of age (35-39, 40-49, $50-59$, and $\geq 60$ ) and hours worked ( $\leq 39,40-49,50-59$, and $\geq 60$ hours), chosen to replicate similar adjustment variables from the ACS analysis. All \$ values normalized to $2008 \$$ according to consumer price index

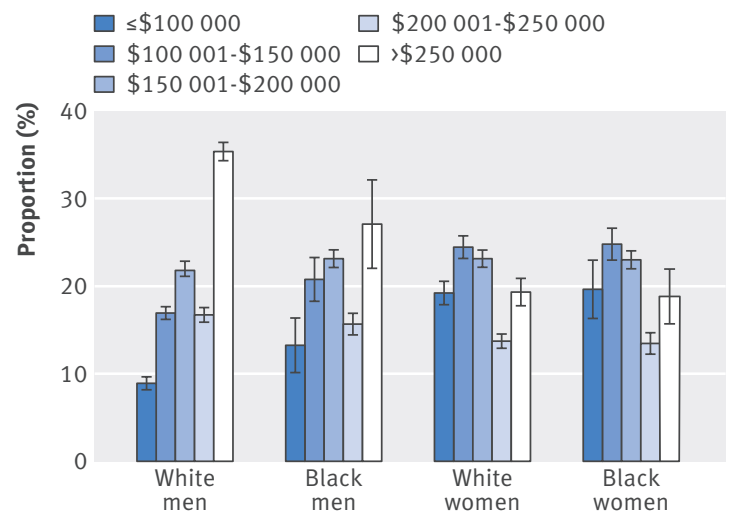

Fig 3 | Income distribution of US physicians in HSC physician surveys (2000-01, 2004-05, 2008) by race and sex. Adjusted as for fig 2 plus adjustments for years in practice, practice type, percentage revenue from Medicare, percentage revenue from Medicaid, and specialty type. All \$ values normalized to 2008 \$ according to consumer price index

compared with $27.1 \%$ (22.1\% to $32.1 \%)$ of black male physicians ( $\mathrm{P}=0.04$ for difference), and $19.4 \%$ (17.9\% to $20.9 \%$ ) of white female physicians earned more than $\$ 250000$ compared with $18.9 \%$ (15.8\% to $22.0 \%$ ) of black female physicians ( $\mathrm{P}=0.36$ for difference). In sensitivity analyses with continuous income values in the first two surveys and replacement of income categories in 2008 with median values of those income categories in 2004-05, the income gap by race among male physicians, after adjustment for specialty and practice characteristics, modestly decreased but remained significant (table $\mathrm{H}$ in appendix). Similarly, results were largely unchanged when we included weeks worked (table I in appendix).

Irrespective of adjustment for physician specialty and practice characteristics, white male physicians therefore had higher annual incomes than black male physicians, whereas white and black female physicians had similar incomes.

\section{Discussion}

\section{Principal findings}

The size and persistence of differences in annual income between black and white US physicians are largely unknown, despite evidence in the overall economy that black workers consistently earn less than white workers. Combining data on physicians' income from two nationally representative surveys, we found that white male physicians earn substantially more than black male physicians, whereas incomes of black and white female physicians are similar to each other, but lower than their male counterparts. These income differences remained after adjustment for physician specialty, hours worked, practice characteristics, insurance mix, and geography. Although income differences between white and black male physicians are substantial, these differences are smaller in magnitude than well documented differences between male and female physicians overall. ${ }^{10-13}$ 


\section{Comparison with previous studies}

The past two decades have witnessed little growth in the proportion of black graduates from US medical schools and substantial growth among women. ${ }^{22}$ Among US graduates, our findings highlight large disparities in income between white and black male physicians, and even larger disparities between male and female physicians. Previous work with smaller samples of black physicians has inconsistently found differences in income between black and white female physicians, ${ }^{6-9}$ whereas we found their incomes to be similar. Our findings more closely reflect income patterns by race in the overall economy-namely, that differences in income among those employed primarily exist among men rather than among women. ${ }^{23}$ While differences in physicians' income by race have received relatively little empirical attention, our findings of large differences by sex are consistent with results of previous studies. ${ }^{10-13}$ For example, in a previous study we estimated the difference in income between male and female physicians in 2006-20 to be $\$ 56019.11$

\section{Potential mechanisms and policy implications}

The etiology of the earnings gap among black and white male physicians is unclear. Black male physicians are more likely to work in primary care and to treat Medicaid patients compared with white male physicians, both of which are associated with lower earnings. Adjustment for these and other practice characteristics, however, did not eliminate-or even substantially reduce-the estimated differences in earnings.

It is possible that differences in patient volume between black and white physicians explain differences in income, but our estimates were unaffected by adjustment for hours worked and practice type, both of which would be expected to be correlated with the average number of patients seen.

Finally, although we adjusted for specialty, there could be differences in subspecialization by race that drive differences in income. For example, race differences could exist within subspecialties of cardiology such as interventional cardiology or electrophysiology; these subspecialty differences might mediate race differences in income even after adjustment for broad specialty. Importantly, even if subspecialty mediates some of the difference in income by race, such differences are still important to understand because differences in subspecialization might not only be because of preferences but also to unequal subspecialty opportunities for black physicians. That is, black physicians might have similar preferences for higher paying subspecialties but less opportunity to enter them.

Outside of healthcare, differences in income by race have been attributed to several factors, including differences in education, labor market attachment, job related skill, and employer discrimination. ${ }^{2}$ Given that physicians reflect a more homogenous, highly educated group than the overall working population and that we adjusted for several factors known to influence physicians' income, it is puzzling why black male physicians earn substantially less than white male physicians.
Among black male physicians, lower bargaining power in salary negotiations with employers, discrimination by employers or patients, and differences in clinical revenue (due to either differences in patient volume, billing, or services provided) remain important considerations that require further exploration.

It is also noteworthy that our findings suggest that while racial disparities are less pronounced among female physicians, this seems to be driven in part by the fact that female physicians earn significantly less than either white or black male physicians. Recent work by us using similar data has documented the persistent differences between male and female physicians, ${ }^{11}$ although others pointed out that these differences could be driven by other factors such as specialty choice or preferences over work hours. ${ }^{24}$ We have confirmed, however, that the differences in earnings between male and female physicians remain large even after adjustment for these other factors. This suggests that some of the factors mentioned above that could drive earnings differences by race among male physicians (negotiating leverage, discrimination, etc) might be even more pronounced for women of all races. It also suggests that race based and sex based disparities in earnings potential cannot be closed simply by opening up opportunities for minorities and women in higher paying specialties. In particular, efforts to eliminate these disparities might need to look beyond medical school admissions and training to the broader workplace.

\section{Strengths and limitations}

Our study had several limitations. First, although the ACS was large and was conducted as recently as 2013, it did not include information on specialty or practice characteristics. In a separate analysis using the HSC physician surveys, however, we showed that estimated income differences by race were unchanged when we adjusted income for these factors. Second, despite a large set of characteristics of physicians and practices available in the HSC physician surveys, the surveys did not include information on patient volume, the types of services provided, and billing practices, all of which could influence income. Third, we could not fully explain why black male physicians receive lower incomes than white male physicians. Fourth, the small sample sizes in the HSC physician surveys precluded an assessment of whether income differences by race varied by specialty. Fifth, income in both surveys is self reported and not independently verified.

\section{Conclusions}

We found substantial differences in annual income between black and white male physicians in the US, and between male and female physicians overall, that persist after adjustment for several characteristics of physicians and practices, including specialty and work hours. Further study is needed to understand the etiology of these race and sex differences and whether they stem from disparities in job opportunity or other factors. 
Contributors: All authors contributed to the design and conduct of the study; data collection and management; analysis and interpretation of the data; and preparation, review, or approval of the manuscript. AB] is guarantor.

Funding: $A B$ J had support from the Office of the Director, National Institutes of Health (NIH Early Independence Award, Grant 1DP50D017897-01) for the submitted work. The research conducted was independent of any involvement from the sponsors of the study. Study sponsors were not involved in study design, data interpretation, writing, or the decision to submit the article for publication.

Competing interests: All authors have completed the ICMJE uniform disclosure form at www.icmje.org/coi_disclosure.pdf and declare: no support from any organization for the submitted work; no financial relationships with any organizations that might have an interest in the submitted work in the previous three years; no other relationships or activities that could appear to have influenced the submitted work

Ethical approval: Not required. All analyzed surveys were deidentified and exempt from human subjects review at Harvard Medical School.

Data sharing: No additional data available.

Transparency statement: The lead author affirms that this manuscript is an honest, accurate, and transparent account of the study being reported; that no important aspects of the study have been omitted; and that any discrepancies from the study as planned (and, if relevant, registered) have been explained.

This is an Open Access article distributed in accordance with the Creative Commons Attribution Non Commercial (CC BY-NC 3.0) license, which permits others to distribute, remix, adapt, build upon this work non-commercially, and license their derivative works on different terms, provided the original work is properly cited and the use is non-commercial. See: http://creativecommons.org/licenses/ by-nc/3.0/.

1 Canon M, Marifian E. Changes in the racial earnings gap since 1960. St. Louis Fed, 2013.

2 Black DA, Kolesnikova NA, Taylor LJ. The Economic Progress of African Americans in Urban Areas: A Tale of 14 Cities. Federal Reserve Bank of St. Louis'. RE:view 2010;92:353-79.

3 U.S. Census Bureau. U.S. Census Bureau. Income.Poverty, and Health nsurance Coverage in the United States, 2011.

4 Lasser KE, Woolhandler S, Himmelstein DU. Sources of U.S. physician income: the contribution of government payments to the specialistgeneralist income gap. J Gen Intern Med 2008;23:1477-81. doi:10.1007/s11606-008-0660-7.

5 Leigh JP, Tancredi D, Jerant A, Kravitz RL. Physician wages across specialties: informing the physician reimbursement debate. Arch Intern Med 2010;170:1728-34. doi:10.1001/archinternmed.2010.350.

6 Weeks WB, Wallace AE. Race and gender differences in general internists' annual incomes. J Gen Intern Med 2006;21:1167-71. doi:10.1111/j.1525-1497.2006.00592.x.
7 Weeks WB, Wallace AE. Association of race and gender with general surgeons' annual incomes. J Am Coll Surg 2006;203:558-67. doi:10.1016/j.jamcollsurg.2006.06.025.

8 Weeks WB, Wallace A. The influence of race and gender on family physicians' annual incomes. J Am Board Fam Med 2006;19:548-56. doi:10.3122/jabfm.19.6.548

9 Weeks WB, Wallace TA, Wallace AE. How do race and sex affect the earnings of primary care physicians? Health Aff (Millwood) 2009;28:557-66. doi:10.1377/hlthaff.28.2.557.

10 Baker LC. Differences in earnings between male and female physicians. N Engl J Med 1996;334:960-4. doi:10.1056/ NEJM199604113341506.

11 Seabury SA, Chandra A, Jena AB. Trends in the earnings of male and female health care professionals in the United States, 1987 to 2010. JAMA Intern Med 2013;173:1748-50.pmid:23999898.

12 Lo Sasso AT, Richards MR, Chou CF, Gerber SE. The $\$ 16,819$ pay gap for newly trained physicians: the unexplained trend of men earning more than women. Health Aff (Millwood) 2011;30:193-201. doi:10.1377/hlthaff.2010.0597.

13 Jagsi R, Griffith KA, Stewart A, Sambuco D, DeCastro R, Ubel PA Gender differences in the salaries of physician researchers. JAMA 2012;307:2410-7. doi:10.1001/jama.2012.6183.

14 Muench U, Sindelar J, Busch SH, Buerhaus PI. Salary differences between male and female registered nurses in the United States. JAMA 2015;313:1265-7. doi:10.1001/jama.2015.1487.

15 Office for National Statistics. Annual survey of hours and earnings, 2013 provisional results. 2013

16 British Medical Association. The pay gap for women in medicine and academic medicine: an analysis of the WAM database. BMA 2009.

17 IPUMS-USA. Wage and salary income. 2016

18 Seabury SA, Jena AB, Chandra A. Trends in the earnings of health care professionals in the United States, 1987-2010. JAMA 2012;308:20835. doi:10.1001/jama.2012.14552.

19 Staiger DO, Auerbach DI, Buerhaus PI. Trends in the work hours of physicians in the United States. JAMA 2010;303:747-53. doi:10.1001/ jama.2010.168.

20 Center for Studying Health System Change. CTS Physician Surveys and the HSC 2008 Health Tracking Physician Survey. 2016.

21 Center for Studying Health System Change. 2008 Health Tracking Physician Survey Restricted Use File: User's Guide. 2010.

22 Association of American Medical Colleges. Diversity in the Physician Workforce: Facts \& Figures 2014. 2014

23 Neal D. The Measured Black-White Wage Gap among Women Is Too Small. J PolitEcon 2004:112:S21-8. doi:10.1086/379940

24 Ambati B. Gender income disparities can be explained by alternative factors. JAMA Intern Med 2014;174:822-3. doi:10.1001/ jamainternmed.2014.48.

(c) BMJ Publishing Group Ltd 2016

Appendix: Supplementary tables A-I 